\title{
SOBRE LA ESPERANZA COMO POSIBILIDAD
}

\author{
Javier PARICIO \\ Universidad Complutense de Madrid \\ j.paricio@der.ucm.es
}

1. Diez años atrás, un entonces (casi) desconocido escritor, Javier Gomá Lanzón, me entregaba un ejemplar del extenso ensayo filosófico que acababa de publicar bajo el título de Imitación y experiencia (Valencia, Pre-textos, 2003, 414 pp.). Su autor había sido alumno - y deslumbrante- de quien suscribe a finales de los años ochenta de la pasada centuria, y ya entonces hablaba como en presente de un amplio proyecto intelectual que tantos años después comenzaba a hacerse realidad. Tras su lectura redacté un comentario de medianas dimensiones ${ }^{1}$ en el que, al releerlo ahora, no he encontrado nada que rectificar. El éxito del primer libro de Javier Gomá sería grande, hasta el punto de obtener, al año siguiente, el Premio Nacional de Ensayo, lo que no tenía precedentes, ni por asomo, en un autor de su edad.

Aquel volumen se vería pronto acompañado, siempre conforme a un plan concebido como completo desde su inicio, por otros dos: Aquiles en el gineceo o Aprender a ser mortal (Valencia, Pre-textos, 2007, 225 pp.), relativo a la configuración de la individualidad o al tránsito en el hombre del estadio estético — infancia y adolescencia - al estadio ético con aceptación (como Aquiles) de la mortalidad, y Ejemplaridad pública (Madrid, Taurus, 2009, 274 pp.), que por las circunstancias históricas concurrentes en el momento de su aparición alcanzó una resonancia tal que el nombre de su autor y el concepto de ejemplaridad iban a quedar indisociablemente unidos mucho más allá del restringido ámbito filosófico. Con ese tercer volumen concluía la que el autor denomina «trilogía de la experiencia de la vida», a la que sirve de complemento, aunque en un plano distinto, el libro que ahora ve la luz: Necesario pero imposible o ¿Qué podemos esperar? (Madrid, Taurus, 2013, 289 pp.), que sirve de cierre al referido proyecto filosófico.

${ }^{1} \mathrm{~J}$. PARICIO, «Imitación y experiencia de la vida», en Seminarios Complutenses de Derecho romano, XV (2003) pp. 215 y ss. 
2. En cierto modo, Necesario pero imposible entronca con Aquiles en el gineceo. Acabo de indicar que éste versa sobre la individualidad y la mortalidad, mientras que el nuevo ensayo trata, desde una perspectiva moderna, sobre si resulta posible admitir que la individualidad se prorrogue más allá de la muerte, es decir, sobre la posibilidad de la esperanza; entendiendo este término, pues, en el ceñido sentido de expectativa transmundana (p. 15). Un problema que, como se encarga de recordar el autor al comienzo de su ensayo, ha sido central en la gran tradición filosófica de Occidente, desde Sócrates hasta Kant, pero que tras éste «desaparece súbitamente como tema filosófico y se entrega in toto a la teología y a la piedad religiosa. ¿Qué tienen que decir sobre el tema nombres como Hegel, Schopenhauer, Nietzsche, Wittgenstein, Heidegger, Ortega o Sartre? Nada. Y la segunda mitad del siglo XX no hace sino confirmar aún más esta tendencia omisiva» (p. 16). Así pues, se trata de una cuestión que la filosofía ha aparcado de manera deliberada desde que, con la Modernidad, rompió toda ligazón con el ámbito religioso o, si se prefiere, desde que «se emancipó de la tutela celeste». Al retomarla ahora y tratar de colocar nuevamente en el primer plano filosófico la cuestión de la esperanza en un más allá de la muerte, el autor asume un reto y un riesgo, pues así como con sus tres primeros libros logró captar de modo significativo la atención del ámbito filosófico que realmente cuenta, pudiera ser que al volver la mirada sobre un tema tan trascendental, pero (para tantos) «tan superado», le sucediese lo que el propio Gomá, en otro contexto, recuerda (pp. 228 s.) que le pasó a Pablo de Tarso en el Areópago cuando fue invitado por filósofos epicúreos y estoicos para que explicara su culto a una divinidad extranjera; al aludir Pablo a la resurrección de Jesús de entre los muertos perdieron la paciencia, le interrumpieron y le despidieron condescendientes: «al oír lo de la resurrección de los muertos, unos se echaron a reír, otros dijeron: te oiremos sobre esto en otra ocasión» (cfr. Hch 17.16 ss.).

Insiste Gomá, en el libro y en la presentación pública del mismo que hizo en el Teatro Real de Madrid, que un tema filosófico tradicional como el que ahora aborda se había convertido en las dos últimas centurias, al admitirse el dogma de que el mundo experimental agota la realidad, en un no tema. Pero con excepciones. Entre ellas menciona, en el libro y en su presentación pública, sólo una: Unamuno, lo que me da pie para referir un recuerdo personal. La primera conversación extensa que mantuve con Juan Iglesias —discípulo epigonal de Miguel de Unamuno, el cual firmó, además, como rector salmantino su primer contrato de docente universitario - se produjo el día en que me incorporaba de modo físico a la Uni- 
versidad de Sevilla, en septiembre de 1984, y digo extensa porque se prolongó, a instancia suya, casi dos horas, durante las que estuvimos paseando en torno a la antigua Fábrica de Tabacos hispalense. Iglesias se había trasladado aquel día a Sevilla con ocasión de una tesis doctoral, y si recuerdo la conversación de modo muy preciso se debe a que fue la primera que mantuvimos y porque en muchos sentidos sería profética. Pues bien, entre otras cosas trató del problema de la perduración más allá de la muerte y recalcó: «como decía Unamuno, ése no es un tema, es "el único tema"».

Gomá es consciente de que así como en sus libros precedentes podía llegar a proponer conclusiones más o menos seguras basadas en la experiencia, ahora eso no será posible, pues, al no poder invocar ésta, deberá limitarse a formular propuestas verosímiles para la mentalidad actual sobre la posibilidad de que la dignidad del hombre —inescindible de su actuación - no tenga como necesario colofón final la indignidad de la muerte. En un momento histórico, por lo demás, poco propicio para ello, pues para la mentalidad y la estética imperantes sólo la muerte y el fracaso parecerían justificar la existencia. El hilo conductor para Gomá vuelve a ser, como en los ensayos anteriores, el de la ejemplaridad, y por eso reaparecen categorías y argumentos que ya comparecieron en los volúmenes sobre la experiencia de la vida. En todo caso, y aunque el autor advierte que en la hora presente la esperanza en la supervivencia post mortem se halla «custodiada y administrada por la teología, la religión organizada y la piedad», mientras él desea reclamarla también para el ámbito filosófico, ello no implica necesariamente ni que a la filosofía le esté vedado servirse de resultados proporcionados por la investigación teológica, ni mucho menos de los aportados por las modernas investigaciones científicas sobre el Jesús histórico. Señala con precisión Gomá que «cuando los discípulos del profeta itinerante, muerto en la cruz, afirmaron que habían visto a éste resucitado - tan individual como antes, aunque fuera del mundo- introdujeron en la historia del pensamiento universal una idea absolutamente novedosa sobre la posibilidad de una supervivencia post mortem, no deducible de préstamos anteriores, y ya sólo por eso una teoría de la esperanza está obligada a tomar en consideración la figura del profeta de Galilea» (denominación preferente ésta, junto a la de galileo, que el autor emplea para referirse a Jesús, al igual que, en general, tiende a evitar en su libro la terminología más propia del ámbito religioso).

Sirviéndose, pues, del hilo conductor de la noción de ejemplaridad, Gomá propone la figura del profeta de Galilea, en absoluto «el mejor de todos», representante de una ejemplaridad histórica tan extraordinaria, 
tan única, que ante ella llegará a frenarse incluso Nietzsche, maldiciente del cristianismo (pp. 194 s.). A esa ejemplaridad — que oscila entre lo extraordinario y lo excepcional, tan exagerada que produce perplejidad y a la que «conviene el título de super-ejemplaridad» (p. 198)—, y a su imitación, se consagra buena parte de libro. Una ejemplaridad, predicada y ratificada por obras, que otorgaba a la predicación del galileo sobre el reino celestial — «de suyo tan poco evidente»— una «credibilidad excepcional». Y una credibilidad que alcanza su cénit en la última semana de la vida de Jesús, cuando se derrama el conflicto con los dos grandes poderes, judío y romano. En este punto Gomá lanza (pp. 206 s.) un guiño, parcial pero inequívoco, a la teología de la liberación (Gutiérrez, Boff, Sobrino), a la que no deja de reconocer el mérito de «haber recuperado la categoría de la conflictividad como atributo inescindible de la figura de Jesús, así como también el haber recordado que todo auténtico seguidor del galileo habrá de padecer pareja persecución». Y una conflictividad, recuerda, que llevaba al profeta de Galilea a emplear las más gruesas palabras contra los poderosos: camada de víboras, idólatras, hipócritas, ciegos y guías de ciegos, sepulcros blanqueados y muchas más, o que, entre tantas otras declaraciones, le llevaba a afirmar que publicanos y prostitutas os precederán en el reino de los cielos; cosas todas ellas que, si no estuvieran recogidas en los evangelios, nos resultarían casi imposibles de creer porque contrastan con la imagen que de él nos ha ofrecido la predicación y la literatura religiosa. Todo lo cual «sugiere una conexión esencial entre ejemplaridad y conflicto», mientras recuerda Gomá que la ejemplaridad, cuando es positiva, «gravita penosamente sobre nosotros, nos abre un juicio y nos obliga a responder del tenor de nuestras vidas, súbitamente bajo sospecha de vulgaridad». «Es evidente que en todo debemos imitar al mejor», según la formulación de Aristóteles en la Ética a Nicómaco (IX, 1171 b 13), y que «el mejor de todos es el galileo» (p. 276), con lo que se cierra la propuesta de imitación.

El profeta de Galilea muere injustamente en la cruz tras un proceso cuya valoración no puede hoy efectuarse seriamente desconociendo las investigaciones modernas dignas de tal nombre ${ }^{2}$. Su super-ejemplaridad hace de su muerte una super-injusticia, hasta el punto de resultar «absoluta y totalmente insoportable» (p. 218). Una muerte que se produce ante

${ }^{2}$ En el ámbito de la lengua española, la primera contribución de ese tipo se debe a J. M. Ribas Alba, El proceso a Jesús de Nazaret. Un estudio histórico-jurídico, 2. ${ }^{a}$ ed., Granada, 2007. En el extenso prólogo se incluye mi valoración de ese estudio. 
un «Dios desconcertante» (pp. 179 ss.) que permitió la trágica experiencia de Jesús, como permitió, por ejemplo, la de Auschwitz. Pero Dios no intervino en esos casos, ni en infinidad de otros, «porque nunca interviene en la exterioridad del mundo». «Esta conclusión, aparentemente antirreligiosa, bien mirado civiliza el infinito porque lo libera del reproche de arbitrariedad y capricho respecto al comportamiento de un Dios que, según la hipótesis providencialista, interfiere unas veces sí y otras no en el orden de la experiencia aplicando en ello un criterio de todo punto incomprensible y hasta ofensivo para las víctimas (la humanidad entera)» ${ }^{3}$. Por eso, a ese Dios maniatado «que se abstiene de mejorar el mundo, sólo le queda un vehículo para canalizar su compasión que en su suelo sufren los hombres: crear una salida a continuación del mundo» (p. 182).

La imitación del galileo no garantiza nada, pues resulta imposible imitarle respecto al acto de resucitar. Para el hombre esto es «tan necesario como imposible», por lo que se hace precisa una palanca exterior que lo genere. Y para que sea portadora de esperanza la causa ejemplar debe funcionar también como causa eficiente, y, por tanto, no basta con ofrecer un modelo para la imitación, sino que debe cooperar activamente en su realización efectiva. La resurrección no da solución al dolor y a la experiencia tantas veces abrumadora del sinsentido y el absurdo de la vida, pero al abrirle una salida «introduce una perspectiva diferente que permite al hombre reinterpretar la totalidad de su experiencia del mundo a la luz de esa posibilidad nueva de lo humano, lo que, en la práctica, supone la restauración de una cierta noción de providencia, si bien no ya en el plano de la experiencia, sino en el de la esperanza» (pp. 247 ss.).

3. La ejemplaridad maltratada y crucificada por el mundo se convierte, con la resurrección, en ejemplaridad encumbrada. Siguiendo a Pannenberg, el «teólogo de la anticipación», el autor (p. 225) admite que la resurrección del galileo es la gran anticipación (die grosse Prolepse) del final de la historia, pues el final de los tiempos ya ha tenido lugar: «el fin de la historia no coincide con su centro, toda vez que éste no se emplaza en el futuro, sino en el pasado».

Respecto a la supervivencia, Gomá habla de modo reiterado, ya desde el mismo inicio de su ensayo (pp. 18 s.), no de una transformación en algo

3 Estando de acuerdo en sustancia con el autor, uno, nacido en una ciudad directamente vinculada al llamado milagro de Calanda — sucedido en 1640 y de cuya historicidad resulta imposible dudar-, tendería a matizar ligeramente la expresión «nunca interviene en la exterioridad del mundo». En todo caso, resulta pueril la imagen divina interviniendo a capricho en las leyes naturales. 
distinto, sino de una mortalidad que no cesa, de una «mortalidad indefinidamente prorrogada», cuestión a la que dedica el que, a mi juicio, es —junto al que lleva por título «Civilizar el infinito» (pp. 159 ss.) — el capítulo central del libro (pp. 215 ss.) y cuya lectura resulta estimulante con independencia de que se acepte o no la interpretación del autor. En este sentido adelanto que, si lo entiendo bien, su planteamiento no estaría muy lejano -nomenclaturas aparte- a lo que es convicción de personas con las que sólo de vez en cuando trato de estas cuestiones y a lo que, de algún modo, puedo considerar, por extensión, como convicción personal.

Cuando Jesús resucitado se aparece en distintas ocasiones, los que lo contemplan son conscientes de que es el mismo que era, pero también de que no es el mismo. Esa «ambigüedad de su estatus» los relatos evangélicos la dejan entrever, en diferentes momentos, con absoluta nitidez. «Algo», pues, ha cambiado. El resucitado se manifiesta, en la expresión de Gomá, «como un cuerpo espiritualizado», terminología quizá preferible a la tradicional de cuerpo glorioso. Un cuerpo que aparece y desaparece, que atraviesa las paredes, de inefable liviandad y agilidad. Un cuerpo en el que, según ha llegado a expresarse de modo feliz, el espíritu ya no está subordinado a la materia, como antes, sino que ésta queda totalmente dominada por el espíritu. Pero, en todo caso, el resucitado no es un nuevo ente, pues, como acertadamente señala Gomá, «se mantiene la mismidad que lo hace reconocible para él mismo y para los otros que lo han tratado. La identidad entre el crucificado y el resucitado constituye el presupuesto de la resurrección» (pp. 232 s.).

Estando de acuerdo con Gomá cuando afirma de modo gráfico (p. 234) que «cualquiera que sea la vida humana que esperamos más allá del mundo no puede dudarse de que en todo caso se compondrá de "carne y sangre" ( (la resurrección sólo puede ser resurrección de la carne, pues apenas sí tendría sentido hablar de resurrección del alma, siendo ésta inmortal), no estoy seguro de poder seguirle, al menos en su literalidad, cuando señala que «yerra la tradición filosófica y teológica cuando concibe la mentada supervivencia post mortem como una inmortalización o eternización del yo» (p. 233). Pues al quedar la materia bajo el control del espíritu, el cuerpo resucitado queda también liberado de todas las servidumbres de la materia, y en ese estadio no parece que tenga sentido hablar de tiempo o de finitud, porque está ya al margen del tiempo. Como tampoco lo tiene hablar del espacio en la vida de la resurrección.

4. Aunque en quien escribe la proximidad a las concepciones de Gomá tiende a ser incomparablemente mayor que las diferencias, sería 
ingenuo ocultar que los interrogantes principales siguen abiertos. En todo caso, el esfuerzo creador que el autor realiza tratando de recuperar el tema de la esperanza para el pensamiento posmoderno es admirable, como lo es la elegancia formal y la accesibilidad con que el texto se presenta.

Concluyo. No recuerdo haber tratado nunca antes por escrito de estas cuestiones. El hacerlo ahora quizá sea, y sin quizá, atrevimiento intolerable, acaso sólo admisible en cuanto diálogo con un antiguo alumno. Las páginas de su ensayo y estos pocos párrafos versan sobre la fe y sobre la esperanza en unos momentos históricos de descreimiento y pesimismo. Por eso, tal vez nada mejor, para terminar, que reproducir una frase procedente del cuarto evangelio - el de Juan-; una frase de acabamiento y profundidad tales que ante ella siempre me ha parecido que palidecen las interpretaciones. Fue pronunciada por Jesús el galileo ante sus discípulos, tras pregunta de uno de ellos, justo en la antesala de la Pasión. Su fuerza y autoridad son sobrecogedoras. Nunca nadie se atrevió a tanto. Nadie dijo nunca nada similar: Yo soy el camino, la verdad y la vida. Es decir: Yo soy el ejemplo o el modelo a seguir; yo soy la verdad absoluta; yo soy la vida sin $f i n^{4} \mathrm{y}$, por tanto, vuestra esperanza. Ego sum via, veritas et vita (Jn 14.6).

${ }^{4}$ Ése es el sentido que vita tiene de continuo en el evangelio de Juan; vid. 3.16, 6.51, 10.28 , etc. 